\title{
Review: antibiotics active against atypical pathogens do not improve community acquired pneumonia more than $\beta$ lactam antibiotics
}

Mills GD, Oehley MR, Arroll B. Effectiveness of $\beta$ lactam antibiotics compared with antibiotics active against atypical pathogens in non-severe community acquired pneumonia: meta-analysis. BMJ 2005;330:456.

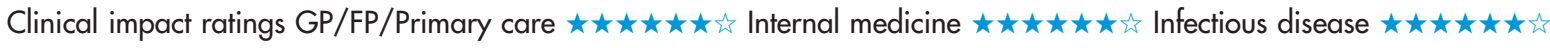

In patients with community acquired pneumonia (CAP), how do antibiotics active against atypical pathogens (AAAAPs) compare with $\beta$ lactam antibiotics for effectiveness?

\section{METHODS}

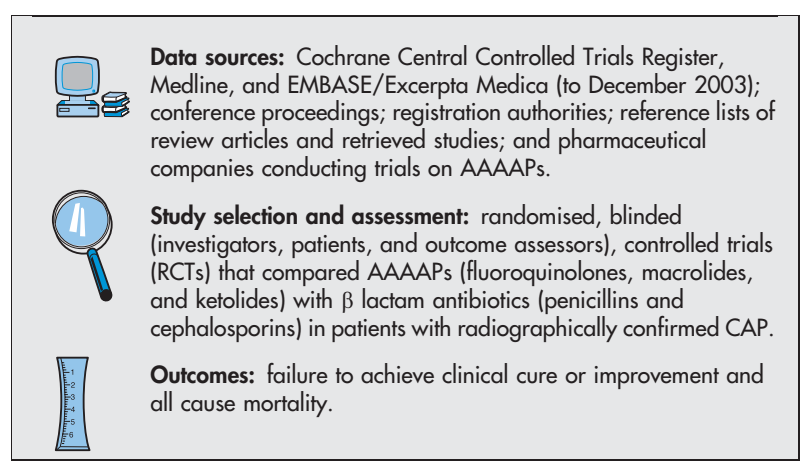

\section{MAIN RESULTS}

18 RCTs $(n=6749)$ met the selection criteria. The trials evaluated 9 different fluoroquinolones, 2 macrolides, and 1 ketolide. Time of outcome assessment ranged from the end of treatment to 38-42 days after commencement of antibiotics. No RCT showed a difference between groups in failure to achieve clinical cure or improvement and no significant heterogeneity existed between studies. Pooled analysis showed no overall difference between groups for failure to achieve cure or improvement and no difference when analyses were done separately on type of AAAAP (table). No treatment effect was seen in patients with Mycoplasma pneumoniae (13 RCTs) (relative risk [RR] $0.60,95 \%$ CI 0.31 to 1.17 ) or Chlamydia pneumoniae (7 RCTs) (RR 2.32, CI 0.67 to 8.03 ), but a reduction in failure to achieve cure or improvement with AAAAPs was seen in patients with Legionella species ( 10 RCTs) (RR 0.40, CI 0.19 to 0.85 ). AAAAPs and $\beta$ lactam antibiotics did not differ for all cause mortality (RR 1.20, CI 0.84 to $1.71)$.

For correspondence: Dr G D Mills, Waikato Hospital, Hamilton, New Zealand. millsg@waikatodhb.govt.nz

Source of funding: Waikato District Health Board.

\section{CONCLUSION}

In patients with community acquired pneumonia, antibiotics active against atypical pathogens and $\beta$ lactam antibiotics do not differ for achieving clinical cure or improvement.

\section{Commentary}

$T$ here are 2 ways in which one can interpret the results of the metaanalysis by Mills et al. One is that patients with pneumonia of mild to moderate severity (apart from those with Legionnaire's disease) do not need to receive AAAAPs (mainly Mycoplasma pneumoniae and Chlamydia pneumoniae) because the host response is sufficient to contain this infection. The second interpretation is that the wrong outcome measures were used in the clinical trials. Time to resolution of symptoms and time to return to work are more likely to be responsive to the intervention in patients with very low mortality caused by pneumonia. I suspect that both interpretations may be correct.

2 previous trials suggest a shorter time to resolution of fever in patients with $M$ pneumoniae and Coxiella burnetii infection treated with AAAAPs. ${ }^{1-2}$ Since such outcomes were not addressed in the review, the question of benefit with AAAAPs remains unresolved.

Despite its limitations, this review confirms the findings of observational studies dating back to the original outbreak of Legionnaire's disease $e^{3-4}$ that indicated that treatment of Legionnaire's disease with AAAAPs improved outcomes. The issue of whether AAAAPs offer an advantage over $\beta$ lactam antibiotics in patients with CAP needs to be addressed in an RCT using appropriate outcomes.

Thomas J Marrie, MD University of Alberta Edmonton, Alberta, Canada

1 Shames JM, George RB, Holliday WB, et al. Comparison of antibiotics in the treatment of mycoplasmal pneumonia. Arch Intern Med 1970;125:680-4

2 Sobradillo V, Zalacain R, Capelastegui A, et al. Antibiotic treatment in pneumonia due to $Q$ fever. Thorax 1992;47:276-8.

3 Fraser DW, Tsai TR, Orenstein W, et al. Legionnaires' disease: description of an epidemic of pneumonia. N Engl J Med 1977;297:1 189-97.

4 Blázquez Garrido RM, Espinosa Parra FJ, Alemany Francés L, et al. Antimicrobial chemotherapy for legionnaires disease: levofloxacin versus macrolides. Clin Infect Dis 2005;40:800-6.

Antibiotics active against atypical pathogens (AAAAPs) $v \beta$ lactam antibiotics in community acquired pneumonia*

\begin{tabular}{|c|c|c|c|c|c|c|}
\hline \multirow[b]{2}{*}{ Outcome at $\leqslant 42$ days } & \multirow[b]{2}{*}{ Type of AAAAP } & \multirow[b]{2}{*}{ Number of trials ( $\mathrm{n}$ ) } & \multicolumn{2}{|c|}{ Weighted event rates } & \multirow[b]{2}{*}{$\operatorname{RRR}(95 \% \mathrm{Cl})$} & \multirow[b]{2}{*}{ NNT } \\
\hline & & & AAAAP & $\beta$ lactam & & \\
\hline $\begin{array}{l}\text { Rate of failure to } \\
\text { achieve clinical } \\
\text { cure or improvement }\end{array}$ & $\begin{array}{l}\text { All } \\
\text { Macrolide or ketolide } \\
\text { Fluoroquinolone } \\
\text { Quinolone or macrolide† }\end{array}$ & $\begin{aligned} 18 & (6749) \\
3 & (566) \\
14 & (5375) \\
1 & (808)\end{aligned}$ & $\begin{array}{l}17.8 \% \\
18.1 \% \\
17.5 \% \\
22 \%\end{array}$ & $\begin{array}{l}18.4 \% \\
19.9 \% \\
17.9 \% \\
23 \%\end{array}$ & $\begin{array}{l}3 \%(-7 \text { to } 13) \\
19 \%(-14 \text { to } 42) \\
1 \%(-11 \text { to } 12) \\
5 \%(-28 \text { to } 29)\end{array}$ & $\begin{array}{l}\text { Not significant } \\
\text { Not significant } \\
\text { Not significant } \\
\text { Not significant }\end{array}$ \\
\hline
\end{tabular}

*Abbreviations defined in glossary; weighted event rates, RRR, NNT, and Cl calculated from data in article using a fixed effects model. tEvent rates are not weighted. 